\title{
Distinctive Immune Response Patterns of Human and Murine Autoimmune Sera to U1 Small Nuclear Ribonucleoprotein C Protein
}

\author{
Minoru Satoh, ${ }^{\star}$ Jenifer J. Langdon, ${ }^{\star}$ Kimberly J. Hamilton, ${ }^{\star}$ Hanno B. Richards, ${ }^{\star}$ David Panka, ${ }^{\ddagger}$ Robert A. Eisenberg, ${ }^{\S}$ \\ and Westley H. Reeves* \\ *Departments of Medicine and Microbiology/Immunology, Thurston Arthritis Research Center and Lineberger Comprehensive Cancer \\ Center, University of North Carolina, Chapel Hill, North Carolina 27599-7280; ${ }^{\ddagger}$ Department of Microbiology, Boston University School of \\ Medicine, Boston, Massachusetts 02118-2394; and ${ }^{\S}$ Department of Medicine, University of Pennsylvania, Philadelphia, Pennsylvania \\ $19104-6100$
}

\begin{abstract}
The U1 small nuclear ribonucleoprotein (snRNP), a complex of nine proteins with U1 RNA, is a frequent target of autoantibodies in human and murine systemic lupus erythematosus (SLE). Anti-Sm antibodies recognizing the $\mathrm{B}^{\prime} / \mathrm{B}, \mathrm{D}$, $\mathrm{E}, \mathrm{F}$, and $\mathrm{G}$ proteins of $\mathrm{U} 1 \mathrm{snRNPs}$ are highly specific for SLE, and are nearly always accompanied by anti-nRNP antibodies recognizing the U1 snRNP-specific 70K, A, and/or $\mathrm{C}$ proteins. Previous studies suggest that human anti-nRNP antibodies recognize primarily the $\mathrm{U} 1-70 \mathrm{~K}$ and $\mathrm{U} 1-\mathrm{A}$ proteins, whereas recognition of $\mathrm{U} 1-\mathrm{C}$ is less frequent. We report here that autoantibodies to U1-C are more common in human autoimmune sera than believed previously. Using a novel immunoprecipitation technique to detect autoantibodies to native U1-C, 75/78 human sera with anti-nRNP/ Sm antibodies were anti-U1-C (+). In striking contrast, only 1/65 anti-nRNP/Sm (+) MRL mouse sera of various Igh allotypes was positive. Two of ten anti-nRNP/Sm (+) sera from $B A L B / c$ mice with a lupus-like syndrome induced by pristane recognized U1-C. Thus, lupus in MRL mice was characterized by a markedly lower frequency of anti-U1-C antibodies than seen in human SLE or pristane-induced lupus. The results may indicate different pathways of intermolecular-intrastructural diversification of autoantibody responses to the components of U1 snRNPs in human and murine lupus, possibly mediated by alterations in antigen processing induced by the autoantibodies themselves. ( $J$. Clin. Invest. 1996. 97:2619-2626.) Key words: anti-Sm antibodies $\bullet$ anti-nRNP antibodies $\bullet$ antinuclear antibodies $\bullet$ systemic lupus erythematosus $\bullet$ MRL/lpr mice
\end{abstract}

\section{Introduction}

The U small nuclear ribonucleoproteins (snRNPs) ${ }^{1}$ are frequent targets of autoantibodies in human and murine systemic lupus erythematosus (SLE) (1-3). Anti-Sm antibodies recognize the proteins $\mathrm{B}^{\prime} / \mathrm{B}, \mathrm{D} 1 / \mathrm{D} 2 / \mathrm{D} 3, \mathrm{E}, \mathrm{F}$, and $\mathrm{G}$, which are

Address correspondence to Westley H. Reeves, Division of Rheumatology and Immunology, University of North Carolina at Chapel Hill, 3330 Thurston Building, CB\# 7280, Chapel Hill, NC 27599-7280. Phone: 919-966-4191; FAX: 919-966-1739; E-mail: reeves.thurston@ mhs.unc.edu

Received for publication 13 October 1995 and accepted in revised form 6 March 1996.

J. Clin. Invest.

(C) The American Society for Clinical Investigation, Inc.

0021-9738/96/06/2619/08 \$2.00

Volume 97, Number 11, June 1996, 2619-2626 shared by U1, U2, U5, and U4-6 snRNPs (3-5), and are highly specific for the diagnosis of SLE $(1,2)$. In contrast, anti-nRNP antibodies are specific for the unique proteins of U1 snRNPs (U1-70K, U1-A, and U1-C) $(3,5)$, although reactivity with a $\mathrm{B}^{\prime} / \mathrm{B}$ epitope that is unique to U1 snRNPs also has been described (6). Anti-nRNP antibodies, unaccompanied by anti$\mathrm{Sm}$, reach the highest titers in mixed connective tissue disease (MCTD) (7), but they also may be seen in SLE and other conditions. The specificities of anti-nRNP antibodies have been characterized by immunoblotting, and it has been suggested that autoantibodies to U1-A and $\mathrm{U} 1-70 \mathrm{~K}$ are most frequent, whereas anti-U1-C antibodies are detected in only $20-70 \%$ of anti-nRNP $(+)$ sera $(5,8-12)$. However, in immunoprecipitation assays using 6-min pulse-labeled cell extracts, nearly all human anti-nRNP $(+)$ sera immunoprecipitate both A and $\mathrm{C}$ (4), suggesting that autoantibodies to native U1-C might be more common than antibodies to the denatured protein. This issue was re-examined in the present studies. In agreement with the pulse-labeling studies, human anti-nRNP sera almost invariably immunoprecipitated native U1-C. Some sera from mice with autoantibodies induced by pristane (13) also immunoprecipitated U1-C. Unexpectedly, however, sera from MRL/ lpr mice, which contain high titer anti-Sm (2) and anti-nRNP (14) antibodies, did not recognize U1-C, even though U1 snRNPs are a primary target of autoimmunity in this strain $(14,15)$. Thus, markedly different frequencies of anti-U1-C antibodies distinguish human SLE and, to a lesser degree, murine pristane-induced lupus, from lupus in MRL/lpr mice. In view of recent evidence supporting the role of intermolecularintrastructural spreading of autoimmunity to multiple components of a particle (14-17), our data raise the possibility that the spreading of autoimmunity to other components of the U1 snRNP particle may proceed by different pathways in murine and human SLE. Clarification of the mechanisms of autoantibody spreading may shed light on the high degree of disease specificity of anti-Sm antibodies in contrast to the lower specificity of anti-nRNP antibodies.

\section{Methods}

$m A b s$. The specificities of murine $m A$ bs specific for $\mathrm{U}$ snRNP proteins, including 2.73 (anti-U1-70 kD) (18), 22G12 (anti-B'/B) (19), Y2 (anti-B'/B and D) (20), 2-12 (anti-D) (19), 7-13 (anti-D) (19), and 2G7 (anti-D) (21) were confirmed by immunoblotting with purified snRNPs $(13,19)$. mAbs 9A9 (anti-U1-A + U2-B"') and 4G3 (antiU2-B"') (22) were provided by Dr. W.J. van Venrooij (University of Nijmegen, The Netherlands).

1. Abbreviations used in this paper: MCTD, mixed connective tissue disease; nRNP, nuclear ribonucleoprotein antigen; snRNP, small nuclear ribonucleoprotein; SSc, systemic sclerosis. 
Human sera. Sera were obtained from patients with SLE or other autoimmune disorders seen at Keio University Hospital, National Murayama Hospital or Fussa Hospital (Tokyo, Japan). Patients were selected on the basis of autoantibodies to nRNP and/or Sm by double immunodiffusion using rabbit thymus extract (2). Additional serum samples were obtained from University of North Carolina Hospitals (Chapel Hill, NC) and The Rockefeller University Hospital (New York, NY). The clinical diagnoses of SLE and scleroderma (systemic sclerosis, SSc) were made based on ACR criteria $(23,24)$. Sjögren's syndrome and polymyositis/dermatomyositis (PM/ DM) were diagnosed based on the criteria of the Ministry of Health and Welfare, Japanese government (25) and Bohan's criteria (26), respectively. Patients with features of two or more of SLE, SSc, and $\mathrm{PM} / \mathrm{DM}$ were classified as MCTD/overlap syndrome.

Murine sera. MRL/lpr $\operatorname{IgH}^{\mathrm{b}}$ or $\operatorname{IgH}^{\mathrm{j}}$ mice (27), and MRL $+/+$ $\left(\mathrm{IgH}^{\mathrm{j}}\right)$ mice were maintained in our breeding facility. Sera were collected from the tail vein of 4-10-mo-old mice. MRL/lpr $\mathrm{IgH}^{\mathrm{e}}$ mice were generated by backcrossing at Boston University, Boston, MA. In some experiments, 2-5-mo-old female BALB/c mice were injected once i.p. with $0.5 \mathrm{ml}$ of pristane, and sera collected 5 mo later were analyzed for anti-Sm and anti-nRNP antibodies as described (13).

Immunoprecipitation. The proteins recognized by human or murine autoimmune sera were evaluated by immunoprecipitation of radiolabeled K562 (human erythroleukemia) cell extract and SDS-PAGE as described (13). The cells were labeled with $\left[{ }^{35}\right.$ S $]$ methionine and cysteine (DuPont-New England Nuclear, Boston, MA), lysed in NET/NP40 buffer (150 mM NaCl, $2 \mathrm{mM}$ EDTA, $50 \mathrm{mM}$ Tris- $\mathrm{HCl} \mathrm{pH}$ 7.5, $0.3 \% \mathrm{NP}-40$ ), containing $0.5 \mathrm{mM} \mathrm{PMSF}, 0.3 \mathrm{TIU} / \mathrm{ml}$ aprotinin, and immunoprecipitated on protein A Sepharose beads (Pharmacia LKB Biotechnology, Inc., Piscataway, NJ) coated with $10 \mu$ l of human sera or $5 \mu \mathrm{l}$ of mouse sera plus $12 \mu \mathrm{l}$ of rabbit anti-mouse IgG $(1 \mathrm{mg} / \mathrm{ml})$. Immunoprecipitates were washed with $0.5 \mathrm{M} \mathrm{NaCl} \mathrm{NET/NP40} \mathrm{(0.5} \mathrm{M}$ $\mathrm{NaCl}, 2$ mM EDTA, $50 \mathrm{mM}$ Tris-HCl, $\mathrm{pH}$ 7.5, 0.3\% NP-40) or mixed micelle buffer $(50 \mathrm{mM}$ Tris- $\mathrm{HCl}, \mathrm{pH} 7.5,150 \mathrm{mM} \mathrm{NaCl}, 2 \mathrm{mM}$ EDTA, $0.5 \%$ SDS, $2.5 \%$ Triton X-100, $0.25 \mathrm{M}$ sucrose). In some experiments, the immunoprecipitates were washed with NET/NP40 buffer containing $0.15,0.5$, or $1.5 \mathrm{M} \mathrm{NaCl}$. In other experiments, the beads were washed with $0.1,0.25,0.5$, or $1.0 \mathrm{M} \mathrm{MgCl}_{2}$, in $50 \mathrm{mM}$ Tris$\mathrm{HCl}, \mathrm{pH} 7.5,150 \mathrm{mM} \mathrm{NaCl}, 2 \mathrm{mM}$ EDTA, $0.3 \% \mathrm{NP} 40$, followed by NET buffer. L-929 cells (murine fibroblast cell line; American Type Culture Collection, Rockville, MD) were radiolabeled, and extract was immunoprecipitated in the same manner. Immunoprecipitated proteins were analyzed by SDS-PAGE and autoradiography (13). When the presence or absence of U1-C in the immunoprecipitates was equivocal, the autoradiograph was scanned and the band densities (volumes) of the U1-A and U1-C proteins were quantified using Image Quant software (Molecular Dynamics, Sunnyvale, CA). If the volume of U1-C was $<10 \%$ that of U1-A after subtracting local background, the sample was classified as anti-U1-C negative.

Immunoprecipitation of free U1-C protein. K562 cell extract derived from $3 \times 10^{6}$ cells was immunoprecipitated with $300 \mu \mathrm{l}$ of $\mathrm{mAb}$ Y2 culture supernatant absorbed on $20 \mu$ l of packed protein A Sepharose beads as above. Immunoprecipitates were washed three times with NET/NP40, and then incubated for $2 \mathrm{~min}$ at $22^{\circ} \mathrm{C}$ with 200 $\mu l$ of either MMB or $0.25 \mathrm{M} \mathrm{MgCl}_{2}, 50 \mathrm{mM}$ Tris-HCl, $\mathrm{pH} 7.5,150 \mathrm{mM}$ $\mathrm{NaCl}, 2 \mathrm{mM}$ EDTA, $0.3 \% \mathrm{NP} 40$. The supernatants were saved, and absorbed twice for $30 \mathrm{~min}$ at $4^{\circ} \mathrm{C}$ with $20 \mu \mathrm{l}$ of packed protein $\mathrm{A}$ Sepharose beads coated with a mixture of $300 \mu 1$ of Y2 culture supernatant, $4 \mu \mathrm{l}$ of 2.73 ascitic fluid, and $200 \mu \mathrm{l} 9 \mathrm{~A} 9$ culture supernatant plus $15 \mu$ l of rabbit anti-mouse IgG, followed by two more absorptions with $20 \mu \mathrm{l}$ of packed protein A Sepharose. The absorbed supernatants were incubated with $5 \mu l$ of either human or murine serum, washed three times with $0.5 \mathrm{M} \mathrm{NaCl} \mathrm{NET/NP40,} \mathrm{and} \mathrm{once} \mathrm{with} \mathrm{NET,}$ and analyzed by SDS-PAGE.

Purification of $U$ snRNPs and immunoblotting. $80 \mu \mathrm{l}$ of $50 \%$ (vol/ vol) protein A Sepharose in $20 \mathrm{mM}$ Tris- $\mathrm{HCl}, \mathrm{pH} 8$, was incubated with $1.5 \mathrm{ml}$ of Y2 (anti-Sm B'/B and D) culture supernatant and the bound antibodies were cross-linked to the beads using dimethyl pime- limidate (28). Y2 mAb-coated beads were then incubated with cell lysate from $10^{8}$ cells in $2 \mathrm{ml}$ of NET/NP40, and washed three times with NET/NP40 and once with NET. These conditions allowed the U1-C protein to remain attached to the beads after washing (see Fig. $1 \mathrm{~A}$, lane 1). The affinity purified proteins were eluted by boiling in SDS sample buffer, fractionated by SDS-PAGE on $12.5 \%$ gels, and transferred to nitrocellulose filters (13). Nitrocellulose strips 2.5 -mm wide were incubated with $0.8 \mathrm{ml}$ of 1:200 human or murine sera or with $\mathrm{mAbs}$ at appropriate dilutions in 5\% non-fat dry milk in PBS at $4^{\circ} \mathrm{C}$ for $16 \mathrm{~h}$. Strips were then washed three times with NET/NP40, incubated with 1:400 alkaline phosphatase-conjugated goat anti-human or mouse $\operatorname{IgG}$ ( $\gamma$ chain specific; Southern Biotechnology, Birmingham, AL) for $3 \mathrm{~h}$ at $22^{\circ} \mathrm{C}$, washed again with NET/NP40, and developed as described (13). The strip incubated with mAb 2G7 (IgG3) was probed with alkaline phosphatase-labeled goat anti-mouse IgG3 antibodies.

\section{Results}

Although U1-C is generally considered to be a less important target of autoantibodies than U1-A and U1-70K $(5,8-12)$, pulse labeling studies (4) suggest that autoantibodies to the native U1-C protein may actually be relatively common. To determine the frequency of autoantibodies to native U1-C, the possibility of dissociating U1-C from the U1 snRNP under mild conditions was evaluated as the basis for a screening assay. U1-C is associated with the U1 snRNP via protein-protein interactions (29), and in view of previous observations that MMB and/or high concentrations of salt disrupt certain protein-protein interactions with relatively little effect on protein-nucleic acid interactions (30), we examined whether U1-C could be released from the U1 snRNP by these treatments.

Dissociation of affinity-purified U1 snRNPs on protein $A$ Sepharose beads. K562 cell extract was immunoprecipitated with the anti-Sm B'/B and D mAb Y2, prototype human antiSm autoimmune serum, or human anti-nRNP serum (positive in double immunodiffusion) as shown in Fig. $1, A, B$, and $C$, respectively, followed by washing with $0.15 \mathrm{M} \mathrm{NaCl} \mathrm{NET/NP40}$ (lane 1), 0.5 M NaCl NET/NP40 (lane 2), $1.5 \mathrm{M} \mathrm{NaCl} \mathrm{NET/}$ NP40 (lane 3), or MMB (lane 4). SDS-PAGE and autoradiography revealed that when the beads were washed with 0.15 or $0.5 \mathrm{M} \mathrm{NaCl}$ NET/ NP40 buffer, all anti-nRNP/Sm sera or mAb immunoprecipitated the proteins A, B'/B, C, D, E, F, G (lanes 1 and 2). In contrast, when the beads were washed with $1.5 \mathrm{M}$ $\mathrm{NaCl}$ NET/NP40 buffer (lane 3), U1-C was only weakly visible in Y2 and anti-Sm immunoprecipitates (Fig. 1, $A$ and $B$, lane $3)$, whereas it remained associated with the anti-nRNP immunoprecipitates with little or no reduction in intensity (Fig. $1 C$, lane 3). The intensity of the $\mathrm{A}, \mathrm{B}^{\prime} / \mathrm{B}$, and $\mathrm{D}$ bands decreased modestly in all three cases (Fig. 1, $A-C$, lane 3 ). The U5 specific $\sim 200-\mathrm{kD}$ doublet was also much fainter after $1.5 \mathrm{M} \mathrm{NaCl}$ washing. When the immunoprecipitates were washed with MMB (lane 4), the U1-C protein was lost completely from Y2 and anti-Sm immunoprecipitates (Fig. 1, $A$ and $B$ ), but not from anti-nRNP immunoprecipitates (Fig. $1 C$ ). Little difference was seen in the intensity of other U1 snRNP subunits after MMB washing, nor was there much change in the intensity of the U5 200-kD doublet, in contrast to what was seen with $1.5 \mathrm{M} \mathrm{NaCl} \mathrm{NET} / \mathrm{NP} 40$ washing. These results suggest that MMB dissociated U1-C from U1 snRNPs, with minimal effect on other components. Moreover, anti-U1-C antibodies retained this subunit on the beads under these conditions.

Immunoprecipitation with $\mathrm{mAbs}$ recognizing components of U1 snRNPs also suggested that U1-C was dissociated from 


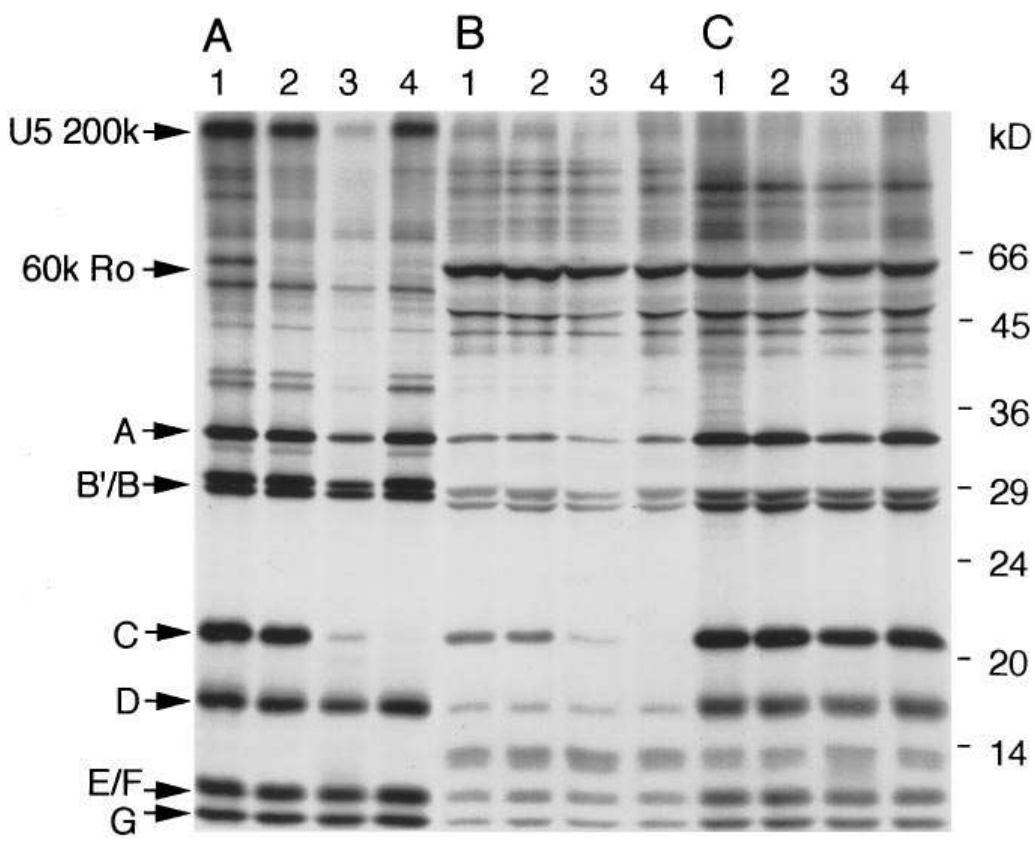

Figure 1. Immunoprecipitation of snRNPs with different washing conditions. Radiolabeled K562 cell extract was immunoprecipitated with $\mathrm{mAb}$ Y2 (anti-Sm B'/B and D), human anti-Sm serum, or human anti-nRNP serum ( $A, B$, and $C$, respectively), followed by washing with buffer containing $0.15,0.5$, or $1.5 \mathrm{M} \mathrm{NaCl}$ (lanes 1-3, respectively) or MMB (lane 4). The U1-70K protein is visualized poorly after labeling cells with $\left[{ }^{35} \mathrm{~S}\right]$ methionine (45) and was not readily apparent here. Note that the U5 $200 \mathrm{~K}$ protein doublet was also dissociated from immunoprecipitates washed with $1.5 \mathrm{M} \mathrm{NaCl}$, but not by MMB washing (cf. lanes 3 and 4, panel $A$ ). Positions of the immunoprecipitated A, $\mathrm{B}^{\prime} / \mathrm{B}, \mathrm{C}, \mathrm{D}, \mathrm{E}, \mathrm{F}, \mathrm{G}$ polypeptides are indicated on the left, along with a prominent $60 \mathrm{~K}$ protein immunoprecipitated by the sera in panels $B$ and $C$, which was identified as the 60K Ro (SS-A) antigen using reference sera (not shown). Positions of molecular weight standards are indicated on the right.
U1 snRNPs by MMB treatment (Fig. 2). Immunoprecipitates with a panel of anti-snRNP mAbs were compared after washing with either $0.5 \mathrm{M} \mathrm{NaCl} \mathrm{NET/NP40} \mathrm{(Fig.} 2 A$ ), or MMB (Fig. 2 B). L-929 cell extract was used because murine cells do not contain the $\mathrm{B}^{\prime}$ protein, facilitating the identification of autoantibodies that immunoprecipitate the U2-B" protein, which has a similar mobility to that of $\mathrm{B}^{\prime}$. U1-C was visible in immunoprecipitates with all of the anti-nRNP and anti-Sm mAbs tested if the beads were washed with $0.5 \mathrm{M} \mathrm{NaCl} \mathrm{NET/}$ NP40 (Fig. $2 A$, lanes $1-7$ ), but was absent if the beads were washed with MMB (Fig. $2 B$, lanes 1-7), with the exception of a weak U1-C signal in the 22G12 lane (Fig. $2 \mathrm{~B}$, lane 3 ). As expected, mAb 4G3 (anti-U2-B' ${ }^{\prime \prime}$ ) and the anti-Ku mAb 162 did not immunoprecipitate the U1-C protein regardless of how the immunoprecipitates were washed (lanes 8 and 9, respectively; the p70 and p80 Ku antigens are not visualized due to the lack of $\mathrm{Ku}$ in L-929 cells [30]). These results further support the in- terpretation that U1-C was dissociated from U1 snRNPs by washing with $\mathrm{MMB}$, but could be retained on the beads by antiU1-C antibodies (Fig. 1). The weak retention of U1-C by $\mathrm{mAb}$ $22 \mathrm{G} 12$ was probably due to crossreactivity of $22 \mathrm{G} 12$ with U1RNP-C, and was confirmed later by immunoblotting (see Fig. 5, lane $c$ ). However, the possibility that the mAb stabilizes the interaction of U1-C with B'/B (29) could not be excluded completely.

Immunoprecipitation with human autoimmune sera. Figs. 1 and 2 suggest that anti-U1-C antibodies retain the U1-C protein on beads after MMB washing. Accordingly, sera from 78 anti-nRNP and/or Sm positive Japanese autoimmune disease patients were screened for anti-U1-C antibodies by immunoprecipitation with MMB washing (Table I). All 54 anti$\mathrm{nRNP}+/ \mathrm{Sm}$ - sera (24 SLE, $25 \mathrm{MCTD} /$ overlap, and $5 \mathrm{SSc}$ ), and anti-nRNP+/Sm+ sera (16 SLE, 4 MCTD/overlap, and one Sjögren's) immunoprecipitated U1-C. In contrast, all three

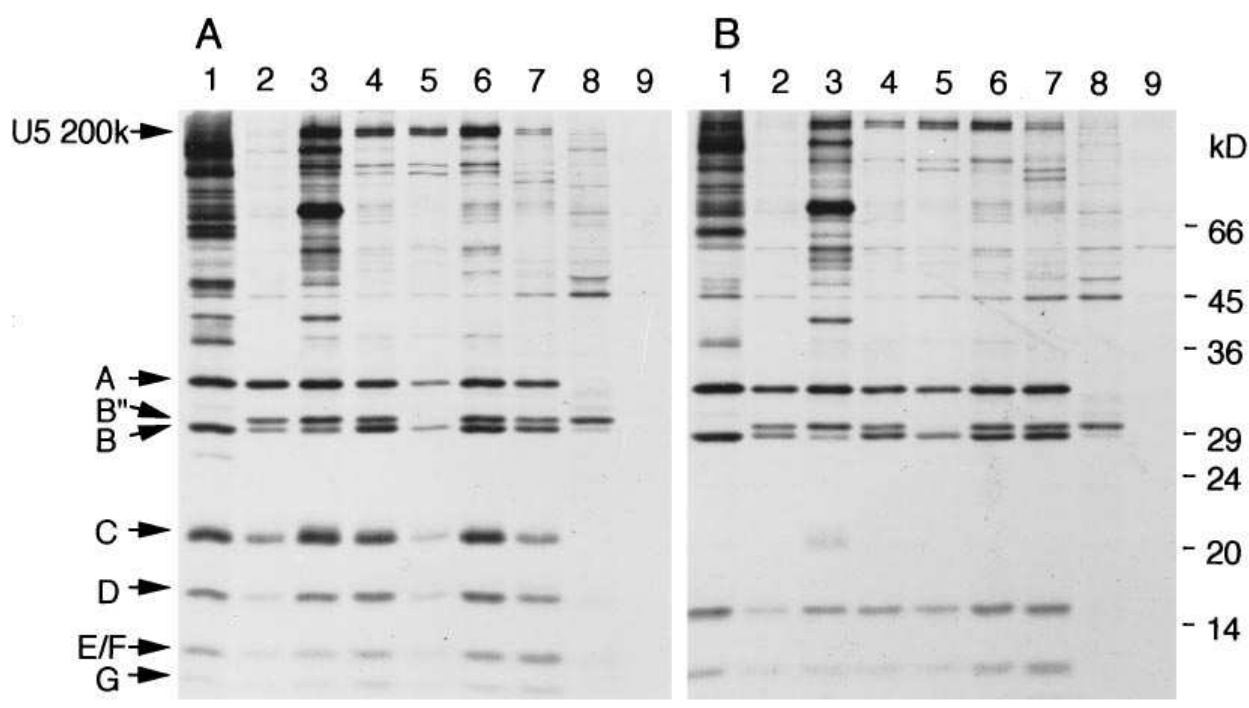

Figure 2. Immunoprecipitation with mAbs to snRNPs. Radiolabeled mouse L929 cell extract was immunoprecipitated with murine mAbs 2.73 (anti-U1-70K, lane 1), 9A9 (anti-U1-A + U2-B" , lane 2), 22G12 (anti-B'/B, lane 3 ), Y2 (anti-B'/B and D, lane 4 ), 2-12 (anti-D, lane 5), 7-13 (anti-D, lane 6), 2G7 (anti-D, lane 7), 4G3 (anti-U2-B" , lane 8), or 162 (anti-Ku antigen, lane 9 ), and washed with $0.5 \mathrm{M} \mathrm{NaCl}$ buffer (panel $A$ ) or MMB (panel $B$ ). 
Table I. Frequency of Autoantibodies to U1-C by Immunoprecipitation and Immunoblotting in Sera from Japanese Patients with anti-nRNP and/or Sm Antibodies

Immunoprecipitation with MMB washing

Human sera*
Anti-nRNP
Anti-Sm+nRNP
Anti-Sm ${ }^{\ddagger}$
Murine sera
MRL/lpr IgH $^{\mathrm{b}}$
MRL/lpr IgH $^{\mathrm{j}}$
MRL/lpr IgH $^{\mathrm{e}}$
MRL $+/+$
BALB/c pristane

$$
\begin{gathered}
100 \%(54 / 54) \\
100 \%(21 / 21) \\
0 \%(0 / 3) \\
\\
0 \%(0 / 12) \\
0 \%(0 / 28) \\
(100 \%, 1 / 1) \\
0 \%(0 / 24) \\
20 \%(2 / 10)
\end{gathered}
$$

$$
\begin{gathered}
26 \%(14 / 54) \\
52 \%(11 / 21) \\
0 \%(0 / 3) \\
\\
\text { n.d. } \\
0 \%(0 / 10) \\
\text { n.d. } \\
0 \%(0 / 10) \\
0 \%(0 / 10)
\end{gathered}
$$

*Specificity defined by double immunodiffusion. ${ }^{\ddagger}$ One serum was completely negative for anti-nRNP precipitin line and did not immunoprecipitate U1-C. Two sera produced an equivocal anti-nRNP precipitin line (line for anti-nRNP was not observed, but anti-nRNP precipitin line deviated around the well with patient's sera). These two sera immunoprecipitated U1-C protein very faintly, but band volumes were $<10 \%$ of the volume of U1-A, and they were defined as anti-U1-C (-) by immunoprecipitation. n.d., not done. ${ }^{\S}$ Defined as anti-Sm and/or nRNP positive by double immunodiffusion.

anti-Sm $+/ \mathrm{nRNP}-\mathrm{SLE}$ sera failed to immunoprecipitate U1-C after MMB washing. In addition to the Japanese patients, we found that immunoprecipitation of U1-C was common in Caucasian (8/8) and Black (25/27) patients with anti-nRNP/Sm antibodies. These results strongly suggest that the immunoprecipitation of U1-C after MMB washing was a nearly universal characteristic of human anti-nRNP/Sm+ sera.

Immunoprecipitation with murine autoimmune sera. MRL/ lpr mice produce anti-Sm and anti-nRNP antibodies and have been studied extensively as a model of autoantibody production in SLE. The presence of anti-U1-C antibodies in sera from MRL/lpr and MRL +/+ mice was evaluated by immunoprecipitating human K562 cell lysate and washing immunoprecipitates with $0.5 \mathrm{M} \mathrm{NaCl} \mathrm{NET/NP40} \mathrm{or} \mathrm{MMB} \mathrm{as} \mathrm{above.} \mathrm{As} \mathrm{ex-}$ pected, all sera that were positive for anti-Sm and/or nRNP by double immunodiffusion immunoprecipitated the A, B'/B, C, $\mathrm{D}, \mathrm{E} / \mathrm{F}$, and $\mathrm{G}$ proteins after $0.5 \mathrm{M} \mathrm{NaCl} \mathrm{NET/NP40} \mathrm{washing.}$ However, unexpectedly, U1-C was absent in all cases when the immunoprecipitates were washed with MMB (data not shown). Although most of the human U1 snRNP subunits have nearly identical sequences to those of the corresponding murine proteins, the sequence of murine U1-C has not been reported. The possibility that murine anti-U1-C might not recognize human U1-C was therefore tested by immunoprecipitating extract from the murine fibroblast cell line L-929, instead of extract from human K562 cells (Fig. 3, $A$ and B). Human prototype sera specific for nRNP (lane 1), nRNP plus Sm (lane 2 ), or Sm alone (lane 3), produced the expected immunoprecipitation patterns after $0.5 \mathrm{M} \mathrm{NaCl} \mathrm{NET} / \mathrm{NP} 40$ or $\mathrm{MMB}$ washing (Fig. 3, $A$ and $B$, respectively). As noted above, murine $U$ snRNPs contain only a single B polypeptide (31) rather than the $\mathrm{B}^{\prime} / \mathrm{B}$ doublet characteristic of human $\mathrm{U}$ snRNPs (cf. Fig. $3 A$, lane 1 with Fig. 1). Human anti-Sm sera (Fig. 3, $A$ and $B$, lanes 2 and 3 ) immunoprecipitated a prominent polypeptide migrating just above Sm-B that has been shown to be the U2$\mathrm{B}^{\prime \prime}$ protein (32). In agreement with the immunoprecipitation studies using K562 extract, sera from four representative MRL/lpr mice (Fig. 3, $A$ and $B$, lanes $a-d$ ), immunoprecipitated all components of L-929 cell U1 snRNPs, including U1-C, when washed with $0.5 \mathrm{M} \mathrm{NaCl} \mathrm{NET/NP40} \mathrm{(Fig.} 3 A$ ). However, after MMB washing, U1-C could not be seen in immunoprecipitates of L-929 cell extract using either human anti-Sm prototype serum (Fig. $3 \mathrm{~B}$, lane 3 ) or MRL/lpr mouse sera (lanes $a-d$ ). Similar results were obtained with an additional 24 anti-Sm (+) sera from MRL +/+ mice, none of which retained U1-C on the beads after MMB washing (Table I).

Screening of sera from MRL allotype congenic mice for anti-U1-C antibodies. Since immunoglobulin allotype can influence autoantibody production in MRL mice $(27,33)$, the U1-C reactivity of sera from anti-Sm/nRNP $(+)$ standard MRL/lpr $\left(\operatorname{IgH} \mathrm{H}^{\mathrm{j}}, n=28\right), \mathrm{MRL} / l p r \operatorname{IgH}^{\mathrm{b}}(n=12)$, and MRL/lpr $\mathrm{IgH}^{\mathrm{e}}(n=1)$ mice was evaluated (Fig. $3 C$, Table I). None of the 28 anti-Sm/nRNP (+) MRL/lpr IgH $\operatorname{Ig}^{\mathrm{j}}$ or $12 \mathrm{MRL} / l p r \mathrm{IgH}^{\mathrm{b}}$ sera retained U1-C on the beads after MMB washing (lanes 8-13 and 1-7, respectively; Table I). The single anti-Sm (+) $\mathrm{MRL} / l p r \mathrm{IgH}^{\mathrm{e}}$ serum retained U1-C on the beads after MMB washing (Fig. $3 C$, lane 14), indicating that, unlike the sera from MRL congenic mice of other allotypes, it contained antiU1-C antibodies. Unfortunately, samples were not available to determine whether the production of anti-U1-C antibodies was a general characteristic of MRL/lpr $\mathrm{IgH}^{\mathrm{e}}$ mice. None of the sera from MRL/lpr or MRL +/+ mice, regardless of allotype, were positive for anti-nRNP alone, since the U2-B' protein and the U5 specific $200-\mathrm{kD}$ doublet were always retained on the beads after MMB washing, along with U1-A and the Sm proteins B, D, E, F, G (Fig. 3). The reactivity with U2- and U5- snRNPs probably reflects anti-Sm antibodies, or less likely, autoantibodies to U2 and U5 snRNP-specific proteins.

Sera from $B A L B / c$ mice with pristane-induced autoimmunity. In contrast to what was seen in MRL mice, anti-nRNP alone was much more frequent in human autoimmune sera (Table I) and in sera from BALB/c mice with a lupus-like syndrome induced by pristane. Two of ten anti-nRNP/Sm (+) sera from $\mathrm{BALB} / \mathrm{c}\left(\operatorname{IgH}^{\mathrm{a}}\right)$ mice injected with pristane exhibited reactivity with U1-C by immunoprecipitation (Table I), even though reactivity with U1-C by immunoblotting is unusual in these mice [(13); see also Fig. 4]. Also, the U5 200-kD 


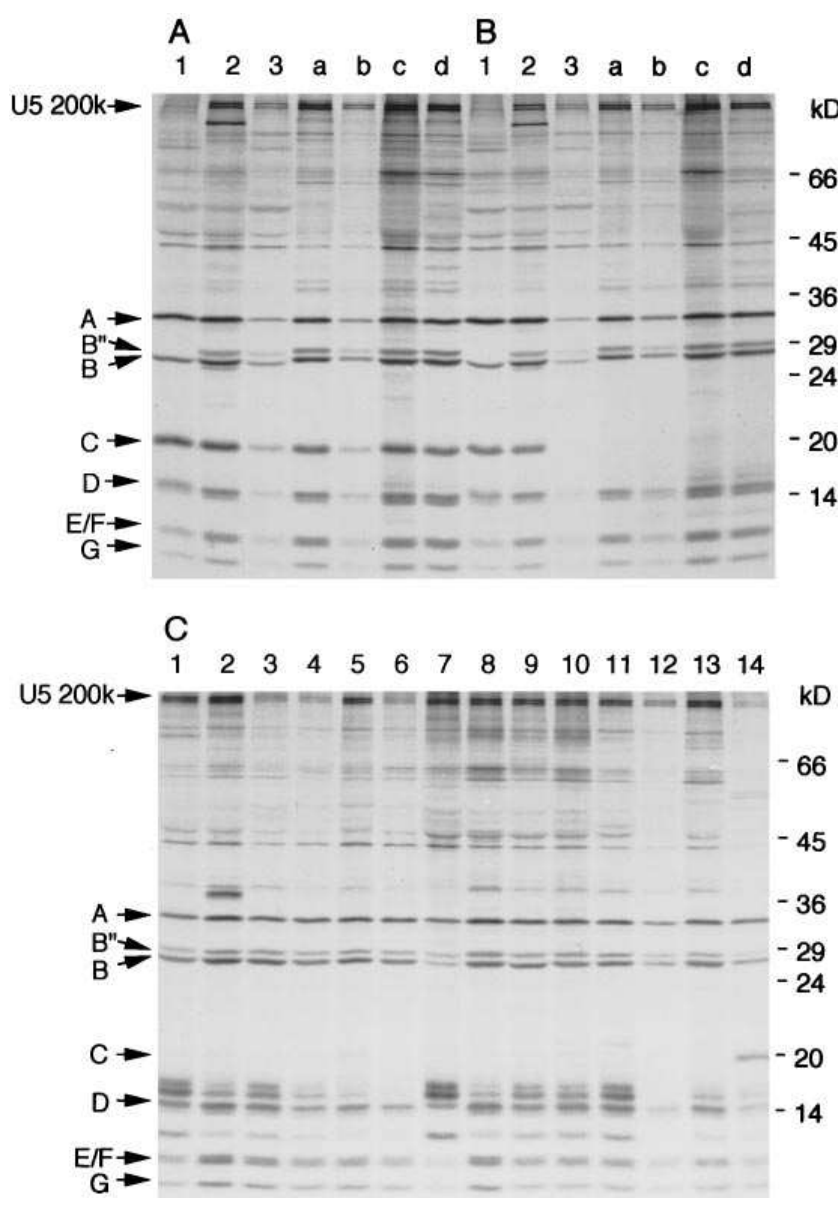

Figure 3. Immunoprecipitation of snRNPs with human and murine autoimmune sera. ( $A$ and $B$ ) Radiolabeled L929 cell extract was immunoprecipitated with human anti-nRNP (lane 1), anti-nRNP and Sm (lane 2), or anti-Sm sera (lane 3) or with MRL/lpr $\left(\operatorname{IgH}^{\mathrm{j}}\right)$ sera (lanes $a-d)$, and washed with $0.5 \mathrm{M} \mathrm{NaCl}$ buffer $(A)$ or MMB (B). (C) MRL allotype congenic mice were screened for anti-U1-C antibodies. Radiolabeled L929 cell extract was immunoprecipitated with MRL/lpr $\operatorname{IgH}^{\mathrm{b}}$ (lanes 1-7), MRL/lpr $\operatorname{IgH}^{\mathrm{j}}$ (lanes 8-13), or $\mathrm{MRL} / l p r \operatorname{IgH}^{\mathrm{e}}$ (lane 14) sera, and washed with MMB. doublet was immunoprecipitated only weakly, primarily late in the course of pristane induced autoimmunity (13).

Immunoprecipitation of free U1-C. Although the above studies suggested that human and murine autoantibodies recognize the U1 snRNP differently, it was not certain whether retention of U1-C on beads was due to direct binding of U1-C by the human, but not murine, autoantibodies, or to a general stabilization of the U1 snRNP structure caused by the binding of autoantibodies to subunits other than U1-C. The failure of anti-Sm prototype serum to retain U1-C on the beads argues against the latter possibility. Nevertheless, the possibility remained that certain anti-nRNP antibodies might prevent the dissociation of U1-C by binding to an epitope comprised of U1-C plus some other subunit, or by an indirect mechanism. This question was addressed by immunoprecipitating biochemically purified U1-C protein.

Since the previous experiments had suggested that U1-C could be released from the U1 snRNP by MMB treatment, the supernatant after MMB washing was immunoprecipitated with human or murine autoimmune sera after extensive immunodepletions to remove all traces of other snRNP polypeptides or intact particles. Most sera that retained U1-C on beads after MMB washing failed to recognize the free U1-C protein after it was released into the supernatant by MMB treatment of U1 snRNPs (data not shown). Since partial denaturation of U1-C by MMB (which contains SDS) might occur, an alternative scheme for purifying U1-C protein was developed, based on treatment of the immunoprecipitates with $\mathrm{MgCl}_{2}$.

When mAb Y2 (anti-Sm B'/B and D) immunoprecipitates of K562 cell extract were washed with $0.15 \mathrm{M} \mathrm{NaCl} \mathrm{NET/NP40}$ buffer containing $0-1.0 \mathrm{M} \mathrm{MgCl}_{2}$, and U1-C was dissociated from U1 snRNPs in the presence of $0.25 \mathrm{M} \mathrm{MgCl}_{2}$ (Fig. $4 \mathrm{~A}$ ). Accordingly, U1-C was eluted from affinity purified U1 snRNPs with $0.25 \mathrm{M} \mathrm{MgCl}_{2}$, and the purified protein was immunoprecipitated with human or murine autoimmune sera (Fig. $4 B$ ). All five human sera containing anti-nRNP antibodies clearly immunoprecipitated U1-C (Fig. 4 B, lanes 1-5), whereas human anti-Sm serum (lane 6), normal human serum (lane 7), and anti-Sm/nRNP (+) MRL/lpr mouse sera (lanes $a-f$ ) did not. These results strongly suggest that the retention of U1-C

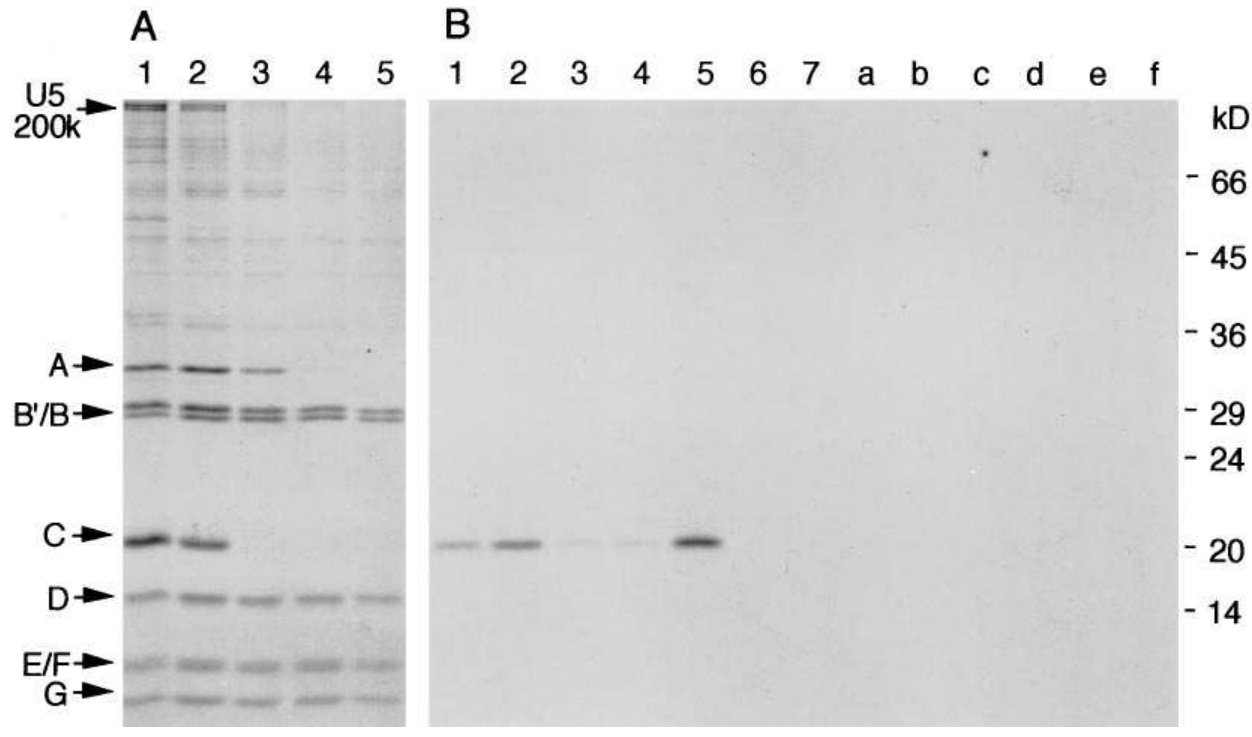

Figure 4. Immunoprecipitation of purified U1-C protein. $(A)$ Immunoprecipitation of snRNPs by $\mathrm{Y} 2$ $\mathrm{mAbs}$ washed with $\mathrm{MgCl}_{2}$. Radiolabeled K562 cell extract was immunoprecipitated with $\mathrm{Y} 2 \mathrm{mAbs}$ and washed with NET/NP40 containing $0,0.1,0.25,0.5$, or $1 \mathrm{M} \mathrm{MgCl}_{2}$ (lanes 1-5, respectively). The U1-C protein was dissociated from U1 snRNPs in the presence of $0.25 \mathrm{M}$ or higher $\mathrm{MgCl}_{2}$ (lanes 3-5). (B) Immunoprecipitation of free U1-C dissociated by $\mathrm{MgCl}_{2}$ buffer. Radiolabeled U1-C was purified from $\mathrm{Y} 2$ immunoprecipitates with $0.25 \mathrm{M} \mathrm{MgCl}_{2}$ as described in the Methods and immunoprecipitated with human anti-nRNP (lanes 1 and 2), anti-nRNP plus Sm (lanes 3-5), or anti-Sm (lane 6) sera, or with normal human serum (lane 7), or with MRL/lpr sera (lanes $a-f)$. 

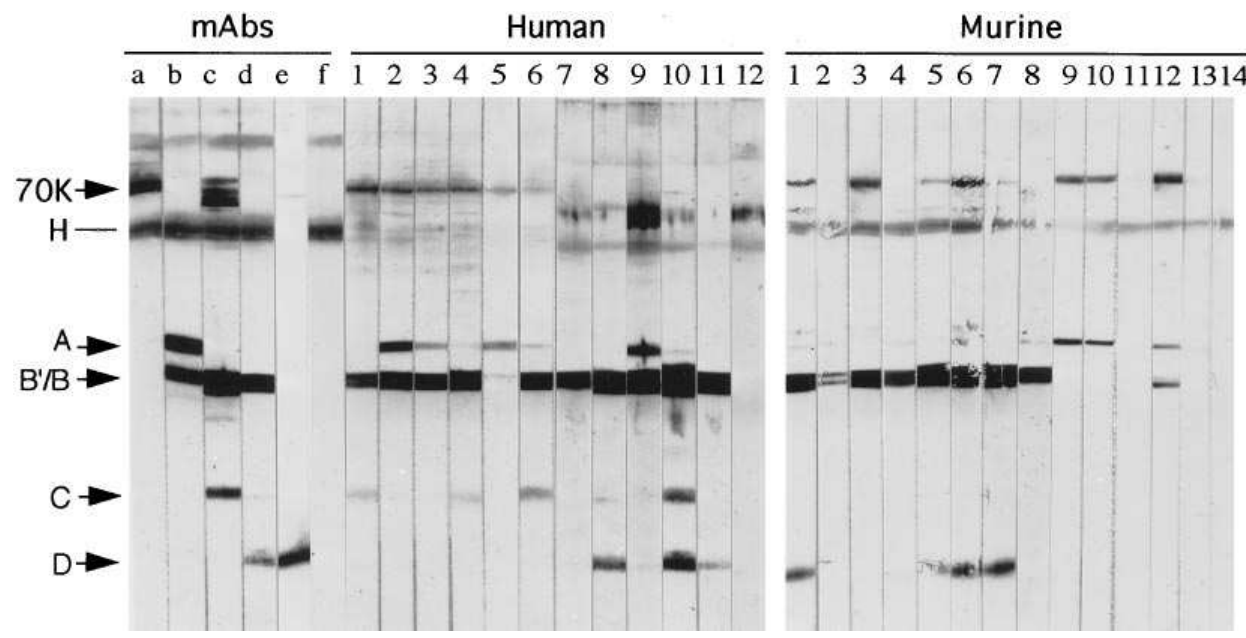

Figure 5. Immunoblot analysis of human and murine autoimmune sera. U snRNPs from K562 cells were affinity purified and transferred to nitrocellulose membrane. Strips of the membrane were probed with mAbs 2.73 (anti-U1-70K, lane $a$ ), 9A9 (anti$\mathrm{U} 1-\mathrm{A}$ and $\mathrm{B}^{\prime \prime}$, lane $b$ ), 22G12 (antiSm B'/B, lane $c$ ), Y2 (anti-Sm B'/B and $\mathrm{D}$, lane $d$ ), 2G7 (anti-Sm D, lane $e$ ), or control mAb 162 (anti-Ku, lane $f$ ), or human autoimmune sera with anti-nRNP (human, lanes 1-6), antinRNP plus anti-Sm (lanes 7-10), or anti-Sm (lane 11) antibodies, or with normal human serum (lane 12). Additional strips were probed with MRL/lpr mouse sera (murine, lanes 1-8), sera from pristane-treated BALB/c mice (lanes 9-13), or antinRNP/Sm negative MRL/lpr mouse serum (lane 14). Positions of the U1-70K, U1-A, U1-C, Sm-B'/B, and Sm-D proteins are indicated on the left. $H$, residual heavy chain from the $\mathrm{mAb}$ used for affinity purification. after MMB washing is at least partially due to antibodies recognizing the U1-C protein itself. In addition, it is likely that the binding of autoantibodies to U1-C partially stabilizes the native conformation in the presence of MMB. It is uncertain whether the epitope(s) involved is (are) dependent on the quaternary structure of the U1 snRNP or the tertiary structure of U1-C. Finally, the inability of human anti-Sm or MRL/lpr sera to immunoprecipitate U1-C after its release from the U1 snRNP by mild $\mathrm{MgCl}_{2}$ treatment suggests that these sera did not recognize determinants of U1-C that were buried within the U1 snRNP particle.

Immunoblot analysis for autoantibodies to U1-C. The present demonstration of a high frequency of autoantibodies to native U1-C in human anti-nRNP (+) sera contrasts with previous data suggesting that autoantibodies to U1-C are relatively uncommon by immunoblotting. Therefore, the sera used in the current study also were tested by immunoblotting (Fig. 5, Table I). To avoid the loss of U1-C during affinity purification, the antigens were affinity-purified using anti-Sm mAb Y2 and washed with NET/NP40 (cf. Fig. $1 A$, lane 1 ). In agreement with previous reports, antibodies to U1-70K, U1-A, and Sm-B'/B were detected in 88\% (69/78), 79\% (62/78), and 97\% (76/78), respectively, of human anti-nRNP/Sm $(+)$ sera. Antibodies to Sm-D were found in $50 \%(12 / 24)$ of anti-Sm $(+)$ patients. However, despite the nearly universal existence of autoantibodies to native U1-C in these samples, by immunoblotting antibodies to U1-C were detected only in 33\% (25/75) of human sera with anti-nRNP antibodies (Fig. 5, Table I), in agreement with previous studies. In addition, the reactivity with U1-C was generally much weaker than that with U1-70K, U1-A or Sm-B'/B. As observed previously (13-15), anti-U1-A and/or U1-70K autoantibodies were detectable by immunoblotting in many MRL mouse sera (Fig. 5, murine, lanes 1-8), but none of sera were reactive with U1-C. Sera from BALB/c mice injected with pristane contained antibodies mainly to U1-70K and U1-A, however, and were unreactive with U1-C, including the two anti-U1-C immunoprecipitation positive sera (Fig. 5, lanes 9-13).

\section{Discussion}

These studies show that nearly all human sera recognizing U1 snRNPs contain autoantibodies to the native U1-C protein. In contrast, such autoantibodies are absent in the sera of MRL/ lpr mice, suggesting that the patterns of autoimmune response to U1 snRNPs are different in human and murine lupus. The epitope(s) recognized by human anti-U1-C antibodies were sensitive to MMB, but were stabilized by prior autoantibody binding, consistent with recent observations that autoantibody binding stabilizes the structure of other antigens (30). The stabilization of antigen structure after antibody binding could have consequences for antigen processing (34) and/or the pattern of intermolecular-intrastructural spreading of autoimmunity.

Selective dissociation of U1-C from U1 snRNPs. Unlike the nRNP-specific U1-70K and U1-A proteins, U1-C lacks an RNA recognition motif $(35,36)$. Consequently, although the association of U1-C with the U1 snRNP is dependent on U1 RNA, it does not bind directly to the RNA $(29,37)$. Instead, U1-C associates with the U1 snRNP particle by interacting with $\mathrm{B}^{\prime} / \mathrm{B}$ (29). MMB or $0.25 \mathrm{M} \mathrm{MgCl}_{2}$ selectively disrupted this protein-protein interaction, releasing U1-C. The dissociation of U1-C from the U1 snRNP by $\mathrm{MMB}$ or $\mathrm{MgCl}_{2}$ allowed us to detect autoantibodies to native U1-C (Fig. 4). This technique made it possible to identify an important difference in the recognition of U1 snRNPs by human and murine autoimmune sera.

Anti-U1-C antibodies are characteristic of human, but not murine, SLE. Immunoprecipitation of U1-C after MMB washing was restricted largely to human autoimmune sera and sera from BALB/c mice with pristane-induced autoimmunity (Table I). Out of 78 anti-nRNP/Sm (+) human sera, 75 were anti$\mathrm{U} 1-\mathrm{C}(+)$, in agreement with previous observations that anti-Sm 
antibodies are usually accompanied by high levels of antinRNP antibodies $(38,39)$. In contrast, only 1 of 65 sera from mice with spontaneous lupus was anti-U1-C $(+)$. Lack of reactivity of murine sera with U1-C was confirmed by immunoprecipitation of biochemically purified U1-C (Fig. 4), arguing strongly against the possibility that the murine sera recognize epitopes of U1-C buried within the interior of the U1 snRNP. However, the crossreactivity of mAb $22 \mathrm{G} 12$ (anti-B'/B, established from an MRL/lpr mouse), with U1-C, along with the equivocal immunoprecipitation of $\mathrm{U} 1-\mathrm{C}$ by some $\mathrm{MRL} / \mathrm{lpr}$ sera (data not shown), suggest that anti-U1-C reactivity may be present at very low titer in some MRL/lpr sera. This is also consistent with the previously reported crossreactivity of human autoantibodies to Sm B'/B with U1-C (40). The fact that U1-C previously bound by autoantibodies was not released by $\mathrm{MMB}$, whereas U1-C generally could not be immunoprecipitated efficiently after its release by MMB, suggests that the antiU1-C antibodies in human autoimmune sera stabilize the conformation of U1-C. However, the variable intensity of the U1-C band in immunoprecipitates using the purified protein (Fig. 4 $B$ ) suggests that certain epitopes are partially dependent on its association with the U1 snRNP particle.

Although autoantibodies to U1-C have been recognized for some time in humans, their reported frequencies have been inconsistent. In vitro translation and pulse labeling experiments with a small number of sera suggest that anti-U1-C antibodies are common in anti-nRNP $(+)$ sera $(4,36)$, in agreement with the present results. However, the frequency of antibodies to U1-C by immunoblotting has been as low as $19 \%$ among anti$\mathrm{nRNP} / \mathrm{Sm}(+)$ sera (9). The immunoblot data in the present report (Fig. 5 and Table I) suggest that the low frequency of anti-U1-C antibodies in previous publications is not a consequence of the use of relatively U1-C-deficient substrates. The low frequency of anti-U1-C antibodies in immunoblot assays is more likely to reflect SDS-sensitivity of U1-C epitopes.

By double immunodiffusion, anti-Sm, rather than antinRNP, is the main specificity seen in MRL/lpr mouse sera (2). However, by immunoblotting, the frequencies of autoantibodies to U1 snRNP specific subunits $70 \mathrm{~K}$ (43\%) and A (100\%) are as high as, or higher than, those of antibodies to the Sm subunits B'/B and D $(14,15)$. Although the frequency of antiU1-C was not addressed in previous studies of the murine immune response to U1 snRNPs, MRL/lpr sera did not exhibit reactivity with U1-C in immunoblotting here (Table I) or in other studies $(14,15)$, suggesting that autoantibodies to native U1-C may be an important component of precipitating antibodies to nRNP. It has been suggested that the initial autoimmune response to U1 snRNPs in MRL/lpr mice is focused on $\mathrm{U} 1-70 \mathrm{~K}$ and U1-A, with subsequent intermolecular-intrastructural diversification leading to the production of anti-Sm B'/B and $\mathrm{D}$ antibodies $(14,15)$. The present data indicate that, in contrast to humans, antibodies to U1-C are extremely rare or absent in MRL/lpr mice, despite the fact that the nRNP antigen is a major target of the autoimmune response in both humans $(38,39)$ and mice $(14,15)$. The reason that the autoimmune response to U1 snRNPs "skips" $\mathrm{U} 1-\mathrm{C}$ in MRL/lpr mice is not known. However, it is likely that anti-U1-C antibodies appear early, since pristane-treated BALB/c mice were positive from the onset of anti-snRNP antibody production, and in the rare case of a patient in whom the onset of anti-snRNP antibodies was observed, anti-U1-C antibodies were also present $(13,41)$.
The striking difference in U1-C recognition between mice and humans might reflect interspecies differences in the structure of U1 snRNPs that alter its immunogenicity. The primary structure of murine U1-C is not known, and could differ from that of the human homologue. Moreover, the murine U1 snRNP contains a single B protein, and the absence of $\mathrm{B}^{\prime}$ might alter its structure sufficiently to reduce the antigenicity of U1-C. For instance, in the murine U1 snRNP, U1-C might be inaccessible to membrane bound Ig on antigen-specific B cells. Finally, differences in the posttranslational modification of U1-C might reduce antigenicity of the murine protein. Pulse-chase studies indicate that the mobility of human (K562 cell) U1-C on SDS gels is reduced gradually over a period of $\sim 8 \mathrm{~h}$ (42). In contrast, this mobility shift occurs very rapidly $(\sim 1 \mathrm{~h})$ in the murine myeloma cell line SP2/0 (M. Satoh, unpublished data). This difference between the human and murine U1 snRNP may also affect antigenicity. However, it remains to be confirmed that the different rates of posttranslational modification of U1-C reflect a general difference between human and murine cells, or a property of the individual cell lines tested.

It is also possible that differences in genetic loci controlling immune responsiveness (e.g., MHC antigens or allotypes), or the effects of exogenous or endogenous infections or other environmental agents, explain the different patterns of U1-C recognition in human and murine lupus. The significance of immunoprecipitation of U1-C by a single MRL/lpr $\mathrm{IgH}^{\mathrm{e}}$ serum and 2/10 sera from pristane-primed BALB/c mice is uncertain at present. Previous studies suggest that Igh allotype influences the production of anti-chromatin and anti-Sm antibodies in MRL/lpr mice $\left(27,33\right.$ ). Thus, the $\operatorname{IgH}^{\mathrm{e}}$ allotype (or $\operatorname{IgH}^{\mathrm{a}}$ of $\mathrm{BALB} / \mathrm{c}$ mice), or products of genes in linkage disequilibrium with the Igh locus, might be associated with enhanced anti-U1-C antibody production. Further studies are needed to address this question. Also, the importance of MHC in autoantibody production has been suggested. For example, production of antifibrillarin antibodies in mice treated with $\mathrm{HgCl}_{2}$ is restricted to $\mathrm{H}-2^{\mathrm{s}}(43,44)$. Therefore, the possibility that anti-U1-C antibody production is associated with $\mathrm{H}-2^{\mathrm{d}}$ must also be considered.

In summary, the present study shows that autoantibodies to the native U1-C protein are nearly universal in human antinRNP/Sm (+) sera. This contrasts with the low frequency of antibodies to U1-C reported previously, and reemphasizes the importance of testing for autoantibodies to native, rather than denatured, proteins. Analysis of the mechanisms responsible for the different autoantibody diversification patterns to components of snRNPs between human, MRL/lpr, and pristanetreated $\mathrm{BALB} / \mathrm{c}$ mice, may offer clues to understand the generation of immune responses to multiprotein complexes and basis for the disease specificity of anti-Sm antibodies.

\section{Acknowledgments}

We thank Dr. Walther J. van Venrooij for providing mAbs, Ms. Sylvia Craven for double immunodiffusion analysis, and Dr. Takashi Ogasawara (Keio University, Tokyo, Japan) for helpful discussions.

This work was supported by grants AR42573, AR40391, AR30701, AR40620, AR26574, AR34156, AR33887, and RR00046 from the United States Public Health Service.

\section{References}

1. Tan, E.M., and H.G. Kunkel. 1966. Characteristics of a soluble nuclear 
antigen precipitating with sera of patients with systemic lupus erythematosus. $J$. Immunol. 96:464-471.

2. Eisenberg, R.A., E.M. Tan, and F.J. Dixon. 1978. Presence of anti-Sm reactivity in autoimmune mouse strains. J. Exp. Med. 147:582-587.

3. Lerner, M.R., and J.A. Steitz. 1979. Antibodies to small nuclear RNAs complexed with proteins are produced by patients with systemic lupus erythematosus. Proc. Natl. Acad. Sci. USA. 76:5495-5499.

4. Fisher, D.E., W.H. Reeves, G.E. Conner, G. Blobel, and H.G. Kunkel. 1984. Pulse labeling of small nuclear ribonucleoproteins in vivo reveals distinct patterns of antigen recognition by human autoimmune antibodies. Proc. Natl. Acad. Sci. USA. 81:3185-3189.

5. Pettersson, I.M., M. Hinterberger, T. Mimori, E. Gottlieb, and J.A. Steitz. 1984. The structure of mammalian small nuclear ribonucleoproteins: identification of multiple protein components reactive with anti-(U1)RNP and anti-Sm antibodies. J. Biol. Chem. 259:5907-5914.

6. Ohosone, Y., T. Mimori, T. Fujii, M. Akizuki, Y. Matsuoka, S. Irimajiri, J.A. Hardin, J. Craft, and M. Homma. 1992. Autoantigenic epitopes of the B polypeptide of Sm small nuclear RNP particles. Identification of regions accessible only within the U1 small nuclear RNP. Arthritis \& Rheum. 35:960-966.

7. Sharp, G.C., W.S. Irvin, E.M. Tan, R.G. Gould, and H.R. Holman. 1972. Mixed connective tissue disease: an apparently distinct rheumatic disease syndrome associated with a specific antibody to an extractable nuclear antigen (ENA). Am. J. Med. 52:148-159.

8. Pettersson, I., G. Wang, E.I. Smith, H. Wigzell, E. Hedfors, J. Horn, and G.C. Sharp. 1986. The use of immunoblotting and immunoprecipitation of (U) small nuclear ribonucleoproteins in the analysis of sera of patients with mixed connective tissue disease and systemic lupus erythematosus. A cross-sectional, longitudinal study. Arthritis \& Rheum. 29:986-995.

9. Francoeur, A.-M. 1989. Anti-SM and anti-U1-RNP lupus antibody fine specificities. J. Clin. Immunol. 9:256-263.

10. Combe, B., M. Rucheton, H. Graafland, V. Lussiez, C. Brunel, and J. Sany. 1989. Clinical significance of anti-RNP and anti-Sm autoantibodies as determined by immunoblotting and immunoprecipitation in sera from patients with connective tissue diseases. Clin. Exp. Immunol. 75:18-24.

11. Habets, W.J., M.H. Hoet, and W.J. van Venrooij. 1990. Epitope patterns of anti-RNP antibodies in rheumatic diseases. Evidence for an antigen-driven autoimmune response. Arthritis \& Rheum. 33:834-841.

12. Lundberg, I., U. Nyman, and E. Hedfors. 1992. Clinical manifestations and anti-(U1)snRNP antibodies: a prospective study of 29 anti-RNP antibody positive patients. Br. J. Rheumatol. 31:811-817.

13. Satoh, M., and W.H. Reeves. 1994. Induction of lupus-associated autoantibodies in BALB/c mice by intraperitoneal injection of pristane. J. Exp. Med. 180:2341-2346.

14. Fatenejad, S., W. Brooks, A. Schwartz, and J. Craft. 1994. Pattern of anti-small nuclear ribonucleoprotein antibodies in MRL/Mp-lpr/lpr mice suggests that the intact U1 snRNP particle is their autoimmunogenic target. J. Immunol. 152:5523-5531.

15. Fatenejad, S., M.J. Mamula, and J. Craft. 1993. Role of intermolecular/ intrastructural B- and T-cell determinants in the diversification of autoantibodies to ribonucleoprotein particles. Proc. Natl. Acad. Sci. USA. 90:12010-12014.

16. Topfer, F., T. Gordon, and J. McCluskey. 1995. Intra- and intermolecular spreading of autoimmunity involving the nuclear self-antigens La (SS-B) and Ro (SS-A). Proc. Natl. Acad. Sci. USA. 92:875-879.

17. James, J.A., T. Gross, R.H. Scofield, and J.B. Harley. 1995. Immunoglobulin epitope spreading and autoimmune disease after peptide immunization: Sm B/B'-derived PPPGMRPP and PPPGIRGP induce spliceosome autoimmunity. J. Exp. Med. 181:453-461.

18. Billings, P.B., R.W. Allen, F.C. Jensen, and S.O. Hoch. 1982. Anti-RNP monoclonal antibodies derived from a mouse strain with lupus-like autoimmunity. J. Immunol. 128:1176-1180.

19. Bloom, D.D., J.L. Davignon, M.W. Retter, M.J. Shlomchik, D.S. Pisetsky, P.L. Cohen, R.A. Eisenberg, and S.H. Clarke. 1993. V region gene analysis of anti-Sm hybridomas from MRL/Mp-lpr/lpr mice. J. Immunol. 150: 1591-1610.

20. Lerner, E.A., M.R. Lerner, C.A. Janeway, and J.A. Steitz. 1981. Monoclonal antibodies to nucleic acid-containing cellular constituents: probes for molecular biology and autoimmune disease. Proc. Natl. Acad. Sci. USA. 78 : 2737-2741.

21. Pisetsky, D.S., S.O. Hoch, C.L. Klatt, M.A. O'Donnell, and J.D. Keene. 1985. Specificity and idiotypic analysis of a monoclonal anti-Sm antibody with anti-DNA activity. J. Immunol. 135:4080-4085.

22. Habets, W.J., M.H. Hoet, B.A. De Jong, A. van der Kemp, and W.J. van Venrooij. 1989. Mapping of B cell epitopes on small nuclear ribonucleoproteins that react with human autoantibodies as well as with experimentally-induced mouse monoclonal antibodies. J. Immunol. 143:2560-2566.
23. Tan, E.M., A.S. Cohen, J.F. Fries, A.T. Masi, D.J. McShane, N.F. Rothfield, J.G. Schaller, N. Talal, and R.J. Winchester. 1982. The 1982 revised criteria for the classification of systemic lupus erythematosus. Arthritis \& Rheum. 25:1271-1277.

24. Masi, A.T., G.P. Rodnan, T.A. Medsger, R.D. Altman, W.A. D'Angelo, and J.F. Fries. 1980. Subcommittee for Scleroderma Criteria of the American Rheumatism Association Diagnostic and Therapeutic Criteria Committee: preliminary criteria for the classification of systemic sclerosis (scleroderma). $\mathrm{Ar}$ thritis \& Rheum. 23:581-590.

25. Homma, M., T. Tojo, M. Akizuki, and H. Yamagata. 1986. Criteria for Sjogren's syndrome in Japan. Scand. J. Rheumatol. 15(Suppl. 61):26-27.

26. Bohan, A., and J.B. Peter. 1975. Polymyositis and dermatomyositis. $N$. Engl. J. Med. 292:344-347.

27. Halpern, M.D., C.L. Fisher, P.L. Cohen, and R.A. Eisenberg. 1992. Influence of the Ig $\mathrm{H}$ chain locus on autoantibody production in autoimmune mice. J. Immunol. 149:3735-3740.

28. Schneider, C., R.A. Newman, D.R. Sutherland, U. Asser, and M.F. Greaves. 1982. A one-step purification of membrane proteins using a high efficiency immunomatrix. J. Biol. Chem. 257:10766-10769.

29. Nelissen, R.L.H., C.L. Will, W.J. van Venrooij, and R. Luhrmann. 1994 The association of the U1-specific $70 \mathrm{~K}$ and $\mathrm{C}$ proteins with U1 snRNPs is mediated in part by common U snRNP proteins. EMBO (Eur. Mol. Biol. Organ.) J. 13:4113-4125

30. Wang, J., M. Satoh, A. Pierani, J. Schmitt, C.H. Chou, H.G. Stunnenberg, R.G. Roeder, and W.H. Reeves. 1994. Assembly and DNA binding of recombinant $\mathrm{Ku}(\mathrm{p} 70 / \mathrm{p} 80)$ autoantigen defined by a novel monoclonal antibody specific for p70/p80 heterodimers. J. Cell Sci. 107:3223-3233.

31. McAllister, G., S.G. Amara, and M.R. Lerner. 1988. Tissue-specific expression and cDNA cloning of small nuclear ribonucleoprotein-associated polypeptide N. Proc. Natl. Acad. Sci. USA. 85:5296-5300.

32. Habets, W., M. Hoet, P. Bringmann, R. Luhrmann, and W. van Venrooij. 1985. Autoantibodies to ribonucleoprotein particles containing U2 small nuclear RNA. EMBO (Eur. Mol. Biol. Organ.) J. 4:1545-1550.

33. Halpern, M.D., S.Y. Craven, P.L. Cohen, and R.A. Eisenberg. 1993. Regulation of anti-Sm autoantibodies by the immunoglobulin heavy chain locus. J. Immunol. 151:7268-7272.

34. Watts, C., and A. Lanzavecchia. 1993. Suppressive effect of antibody on processing of T cell epitopes. J. Exp. Med. 178:1459-1463.

35. Yamamoto, K., H. Miura, Y. Moroi, S. Yoshinoya, M. Goto, K. Nishioka, and T. Miyamoto. 1988. Isolation and characterization of a complementary DNA expressing human U1 small nuclear ribonucleoprotein C polypeptide. J. Immunol. 140:311-317.

36. Sillekens, P.T.G., R.P. Beijer, W.J. Habets, and W.J. van Venrooij. 1988 Human U1 snRNP-specific C protein: complete cDNA and protein sequence and identification of a multigene family in mammals. Nucleic Acids Res. 17: 8307-8321.

37. Nelissen, R.L., V. Heinrichs, W.J. Habets, F. Simons, R. Luhrmann, and W.J. van Venrooij. 1991. Zinc finger-like structure in U1-specific protein C is essential for specific binding to U1 snRNP. Nucleic Acids Res. 19:449-454.

38. Mattioli, M., and M. Reichlin. 1973. Physical association of two nuclear antigens and mutual occurrence of their antibodies: the relationship of the Sm and RNA protein (Mo) systems in SLE sera. J. Immunol. 110:1318-1324.

39. Reeves, W.H., D.E. Fisher, R.G. Lahita, and H.G. Kunkel. 1985. Autoimmune sera reactive with Sm antigen contain high levels of RNP-like antibodies. J. Clin. Invest. 75:580-587.

40. Habets, W.J., P.T.G. Sillekens, M.H. Hoet, G. McAllister, M.R. Lerner, and W.J. van Venrooij. 1989. Small nuclear RNA-associated proteins are immunologically related as revealed by mapping of autoimmune reactive B-cell epitopes. Proc. Natl. Acad. Sci. USA. 86:4674-4678.

41. Satoh, M., H. Yamagata, F. Watanabe, Y. Matsushita, K. Sakamoto, K. Yoshida, S. Nakayama, and M. Akizuki. 1993. A case of long-standing classical rheumatoid arthritis complicated by serological and clinical characteristics of SLE. Scand. J. Rheumatol. 22:138-140.

42. Fisher, D.E., G.E. Conner, W.H. Reeves, R. Wisniewolski, and G. Blobel. 1985. Small nuclear ribonucleoprotein particle assembly in vivo: demonstration of a $6 \mathrm{~S}$ RNA-free core precursor and posttranslational modification. Cell. 42:751-758.

43. Reuter, R., G. Tessars, H.W. Vohr, E. Gleichmann, and R. Luhrmann 1989. Mercuric chloride induces autoantibodies against U3 small nuclear ribonucleoprotein in susceptible mice. Proc. Natl. Acad. Sci. USA. 86:237-241.

44. Hultman, P., S. Enestrom, K.M. Pollard, and E.M. Tan. 1989. Antifibrillarin autoantibodies in mercury-treated mice. Clin. Exp. Immunol. 78:470477.

45. Craft, J. 1992. Antibodies to snRNPs in systemic lupus erythematosus Rheum. Dis. Clin. North Am. 18:311-335. 